\title{
PREMISSAS PARA A ELABORAÇÃO DO PLANO DE EDUCAÇÃO AMBIENTAL PARA A ÁREA DE PROTEÇÃO AMBIENTAL DO BANHADO GRANDE
}

\author{
Aurici Azevedo da Rosa \\ Especialista em Educação Ambiental/UFSM, auricidarosa@gmail.com
}

http://dx.doi.org/10.5902/223613087087

\section{RESUMO}

A Área de Proteção Ambiental do Banhado Grande - APABG é uma área extensa que envolve uma diversidade de habitats, fauna e flora, além de abranger quatro municípios Viamão, Gravataí, Glorinha e Santo Antônio da Patrulha. Sendo uma APA, ela constitui-se em um tipo de unidade de conservação de uso sustentável. Com poucos anos de existência, ainda é pouco conhecida e sofre com os mais variados tipos de degradação. O presente trabalho pretende elencar pressupostos teóricos e metodológicos que colaborem com a elaboração do Plano de Educação Ambiental para essa unidade. Para tanto, realizou-se uma revisão bibliográfica e duas pesquisas quantitativas; onde, a primeira, teve como objetivo diagnosticar o nível de conhecimento a respeito da APABG e do Refúgio da Vida Silvestre Banhado dos Pachecos - uma unidade de conservação inserida dentro da APA. Essa pesquisa foi realizada na região de Águas Claras/Viamão. A segunda pesquisa foi o mapeamento de ações em Educação Ambiental nos municípios constituintes da Unidade. Com isso, pretendeu-se formar um arcabouço de conhecimentos associados a sua realidade e a toda complexidade das relações ambientais e sociais da região servindo assim, de orientação e embasamento para a elaboração do referido Plano e de proposta para formação de educadores ambientais para a APA visando a sua sustentabilidade. Os pressupostos teóricos se baseiam na formação da cidadania e da consciência ecológica, tendo-se por base a Educação Ambiental Crítica.

Palavras-chave: Plano de Educação Ambiental. Sustentabilidade. Educadores Ambientais.

\section{ABSTRACT}

The Environmental Protection Area of Banhado Grande - APABG is a large area, which involves a diversity of habitats, fauna and flora, besides covering four municipalities Viamão, Gravataí, Glorinha and Santo Antônio da Patrulha. Being a APA, it is a type of protected area for sustainable use. With few years of existence is still little known and suffers from all kinds of degradation. This work intends to list theoretical and methodological assumptions that collaborate with the development of Environmental Education Plan for this unit. To this end, there was a literature review and two quantitative research where the first, aimed to diagnose the level of knowledge reagarding APABG and the "Refúgo da Vida Silvestre Banhado dos Pachecos", a conservation unit inserted into the APA. This survey was conducted in the region of Águas Claras / Viamão. The second survey was the mapping of actions in the environmental education in the constituent municipalities of the unit. This was intended to form a framework of knowledge associated with all their reality and complexity of environmental and social relations in the region serving thus, guidance and foundation for the preparation of the plan and the proposal for formation of environmental educators for the APA, aiming its sustainability. The theoretical assumptions are 
based on the formation of citizenship, environmental awareness and on the Critical Environmental Education.

Keywords: Plan for Environmental Education. Sustainability. Environmental Educators.

\section{INTRODUÇÃO}

A Área de Proteção Ambiental do Banhado Grande - APABG constitui-se em uma unidade de conservação de uso sustentável recentemente estabelecida. Ela possui uma dinâmica biológica rica e uma estrutura física importante no estabelecimento de muitas espécies e no fornecimento de recursos hídricos. Ainda pouco conhecida por seus habitantes essa área sofre com a ocupação humana desordenada e o uso do solo para agricultura dentre outras ações antrópicas. Sem um plano de manejo, que se encontra atualmente em fase de execução, a APABG é uma região sensível que requer um cuidado especial.

Acredita-se que estabelecer um plano de educação ambiental, além do plano de manejo, possa contribuir na melhoria do uso e ocupação dessa área. Ambos constituem-se em instrumentos de regramento e de fonte de conhecimento, que favorecem a preservação, o cuidado e o apreço por um ambiente de beleza cênica e biológica.

Para tanto, tem-se por objetivos: realizar uma análise e compilação de estudos a respeito dos aspectos ambientais da APA do Banhado Grande, tais como os hidrológicos, geológicos, biológicos, ecológicos e também os sociais entrelaçando-os e contextualizando-os; elencar bases teóricas de uma Educação Ambiental Crítica que favoreçam a formação de cidadania e o cuidado e; realizar um levantamento de dados a respeito do nível de conhecimento que comunidade local tem sobre APA e um mapeamento de ações de educação ambiental realizadas na região. Com base em todas essas informações, pretende-se elencar premissas capazes de fundamentar a elaboração de um Plano de Educação Ambiental para essa unidade de conservação.

\section{PREMISSAS PARA A ELABORAÇÃO DE UM PLANO DE EA PARA A APABG}

A Área de Proteção Ambiental do Banhado Grande - APABG possui características próprias que devem ser consideradas na elaboração de um Plano de Educação Ambiental. Criada em 23 de outubro de 1998 ela é bastante extensa, 137.000 hectares, abrangendo quatro municípios, que são: Glorinha; Gravataí; Santo Antônio da Patrulha e Viamão (RIO GRANDE DO SUL, 2010, p. 6), sendo estes dois últimos os que abrigam a maior parte da APABG. Além disso, possui uma estrutura física diversificada, formada por mosaicos de matas de restinga, mata atlântica, dunas, banhados, turfeiras, etc (ACCORDI, 2003, p. 15), proporcionando uma riqueza biológica de fauna e flora. Sendo uma "unidade de uso sustentável" deve "compatibilizar conservação da natureza com uso sustentável" (BRASIL, 2000, p. 4).

Dentro da APABG encontra-se inserida outra unidade de conservação, o Refúgio da Vida Silvestre Banhado dos Pacheco, localizado em Águas Claras/Viamão. Segundo o SNUC (Brasil, 2000 , p. 4) ela se insere na categoria de "Unidades de Proteção Integral" e, em seu Art. 13 esse tipo de unidade tem por objetivo: "[...] proteger ambientes naturais onde se asseguram condições 
para a existência ou reprodução de espécies ou comunidades da flora local e da fauna residente ou migratória" (BRASL, 2000, p. 4).

Aqui são encontradas espécies de fauna e flora ameaçadas de extinção, como o cervo-dopantanal (Blastocerus dichotomus), considerado o maior cervídeo brasileiro e se caracteriza por habitar áreas úmidas da América do Sul (FIGUEIRA et al, 2005). O jacaré-do-papo-amarelo (Caiman latirostris) amplamente distribuído pela America do Sul e que usa esta área para nidificar seus ovos, dentre outras espécies de fauna. A APABG também possui espécies da flora imunes ao corte (RIO GRANDE DO SUL, 2009), conforme o Código Florestal Estadual, como a figueira (Fícus organensis) e as coticeiras-do-banhado (Erythrina crista-galli), que servem de abrigo para ave fauna residente e migratória (RIO GRANDE DO SUL, 2009).

A APA do Banhado Grande tem importância significativa na formação do rio Gravataí (Figura 1), pertencendo a sua bacia hidrográfica $\left(2.293,99 \mathrm{~km}^{2}\right)$, tendo em seu sistema, conforme o termo de referência para o plano de manejo (RIO GRANDE DO SUL, 2010, p. 6), três banhados formadores desse rio: "Banhado Grande nos municípios de Gravataí e Glorinha; Banhado do Chico Lomã, no município de Santo Antônio da Patrulha; e Banhado dos Pachecos, no município de Viamão" (RIO GRANDE DO SUL, 2010, p. 6). O Banhado Grande é o que regula a vazão desse rio, segundo relatório da Fepam, sobre Qualidade das Águas da Bacia Hidrográfica do Rio Gravataí (RIO GRANDE DO SUL [2010?]), esse banhado "originalmente ocupava uma área de $450 \mathrm{~km}^{2}$, sendo reduzido para apenas 50 km², em função do uso da água para irrigação das culturas de arroz".

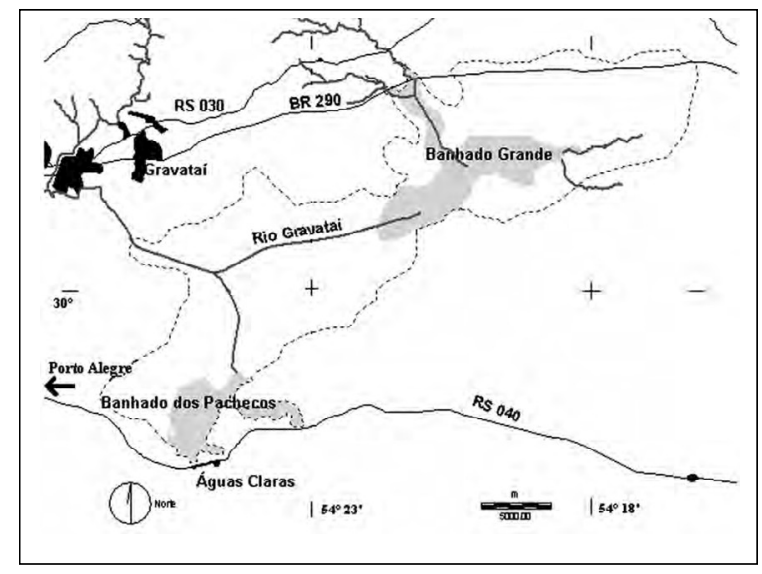

Figura 1 - Localização do Banhado dos Pachecos (em cinza) na região metropolitana de Porto Alegre e no Sistema Banhado Grande (área tracejada). (Fonte: Artigo Distribuição espacial e sazonal da avifauna em uma área úmida costeira do sul do Brasil; lury Almeida Accordi1,2 e Sandra Maria Hartz1)

Frente a toda essa realidade, a elaboração de um plano de educação ambiental para a APABG torna-se fundamental e urgente, no sentido de fazer a população local conhecê-la, sentirse parte dela e protegê-la. Neste sentido, o plano de EA deve possuir mecanismos que possibilitem a sensibilização e o conhecimento da realidade da unidade e de seu entorno, ambos devem provocar nas pessoas o sentido de pertencimento, de querer cuidar e participar nas decisões e nas questões relacionadas à gestão da APABG. Conforme Vendrametto são necessários: 
Programas de educação ambiental, que propiciem o aumento do conhecimento, mudança de valores e o aperfeiçoamento de habilidades, que são condições básicas para que o ser humano assuma atitudes e comportamentos que estejam em sintonia com o meio. (VENDRAMETTO, 2004, p. 45)

Esse sentido de pertencimento deve ser interiorizado, proporcionando assim mudança de condutas assumindo atitudes e comportamentos não pontuais, mas como uma norma de vida, sendo outra forma de encarar as questões sociais e ambientais, ou seja, formando "uma atitude ecológica e cidadã" (CARVALHO, 2004, p. 181).

Com isso, o sujeito passa a ser cooparticipante, concebendo o ambiente como a sua casa, que requer cuidado, carinho e preservação. Para Morin (2005, p. 76) é o "aprender a 'estar aqui' no planeta" e isso "significa: aprender a viver, a dividir, a comunicar", bem distinto do que se vê no mundo do consumo que valoriza o eu, o meu e o ter.

Neste sentido, o plano de EA para a APABG, deve elencar em seus objetivos a pesquisa, a produção de material didático e a formação de educadores e multiplicadores ambientais. Aproveitar e valorizar os conhecimentos que a comunidade possui da região, integrando e trabalhando com aprendizagem significativa, desenvolvendo a postura crítica em um processo continuo (CARVALHO, 2004, p. 185).

Além disso, em um programa de Educação Ambiental para uma unidade de conservação é imprescindível a participação das escolas locais, pois sua amplitude, seu alcance vão além dos muros da escola atingindo toda a comunidade escolar, por isso é interessante que a formação comece pelas instituições de ensino, capacitando os educadores das escolas da região. Fazendo com que estes educadores se sintam parte do processo e capazes de propiciar aos educandos a reflexão crítica sobre as questões ambientais, econômicas, sociais, tecnológicas, tornando-se educadores e educandos agentes da mudança individual e coletiva (BRSIL, 2004, p. 31).

Esse plano apesar de ser único para a APABG deve respeitar as especificidades de cada município que a compõem. Neste sentido, torna-se interessante conhecer o que já existe em educação ambiental, formal e não-formal, na região da APA. Fazer um diagnóstico contribui não só para constatar a existência de EA, como também, que tipo de ações são desenvolvidas, seu grau de articulação com a comunidade local e os temas abordados, criando um sistema de rede de educadores em EA (MMA, 2005, p. 1), a fim de promover a troca, o enriquecimento e o fortalecimento dessas ações.

Outro tipo de pesquisa constitui-se em avaliar o grau de conhecimento que a população local possui a respeito de unidades de conservação e se sabem da existência de alguma na região. Tais dados devem nortear o plano direcionando no que seja mais significativo e adequado. 


\section{MATERIAIS E MÉTODOS}

Aqui se pretende analisar os dados coletados através de duas formas de pesquisa quantitativa com o objetivo de se conhecer e analisar duas realidades.

Em uma delas foi aplicado um questionário com o objetivo de se verificar o grau de conhecimento que a comunidade de Águas Claras/Viamão possui sobre unidades de conservação e, em especial, a APA do Banhado Grande e o Refúgio da Vida Silvestre Banhado dos Pachecos. Este questionário foi aplicado principalmente em duas escolas municipais da região e também na comunidade do entorno das mesmas.

Na segunda pesquisa a intenção foi mapear e analisar as ações em Educação Ambiental realizadas nos quatro municípios que compõem a APA, a fim de se verificar como são feitas, se seguem alguma orientação, custo, o grau de conhecimento sobre essas unidades de conservação, os temas geradores etc.

Na primeira pesquisa, realizada na comunidade de Águas Claras, foram analisados 145 questionários, destes $53,8 \%$ respondidos pelo sexo feminino e $46,2 \%$ masculino. $O$ nível de escolaridade se distribuiu conforme a figura 2.
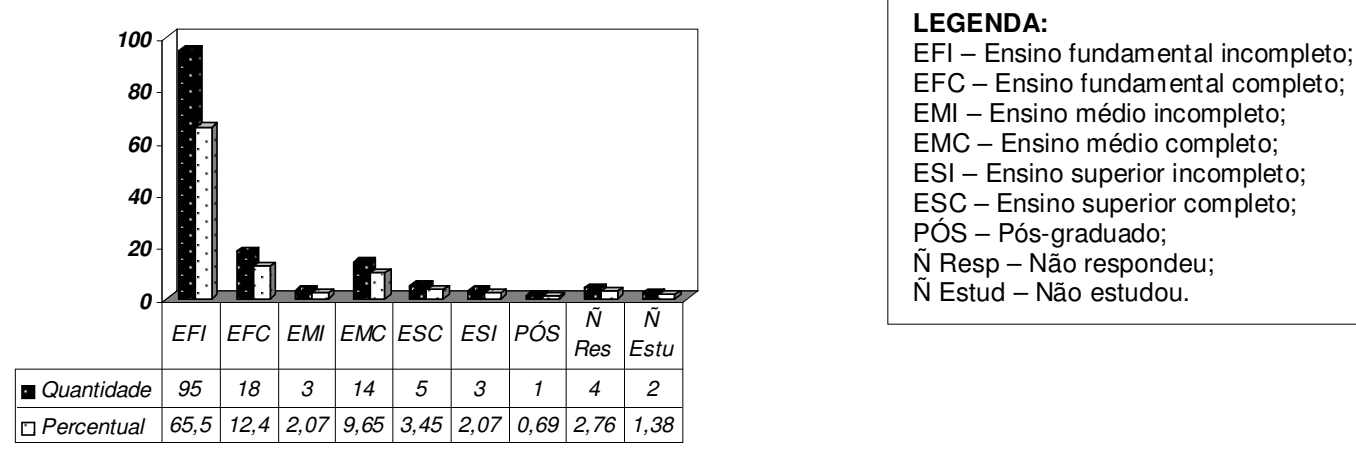

Figura 2 - Gráfico de distribuição do nível de escolaridade dos entrevistados

Quanto ao conhecimento sobre o que é uma Unidade de Conservação (UC) $43,45 \%$ afirmaram que conhecem e $51,72 \%$ responderam que não sabem o que é e 4,83 não responderam.

Em relação à pergunta se já ouviu falar na Área de Proteção Ambiental Banhado Grande $A P A B G$, as respostas se distribuíram da seguinte maneira (Figura 3): 


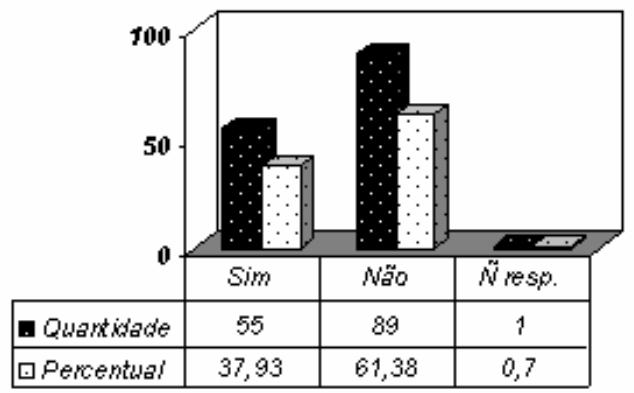

Figura 3 - Gráfico que apresenta a quantificação do nível de conhecimento a respeito da Área de Proteção Ambiental Banhado Grande.

Já em relação ao Refúgio da Vida Silvestre Banhado dos Pachecos constata-se que muitas pessoas $(66,21 \%)$ não conhecem esta unidade de conservação, de acordo com a figura 4:

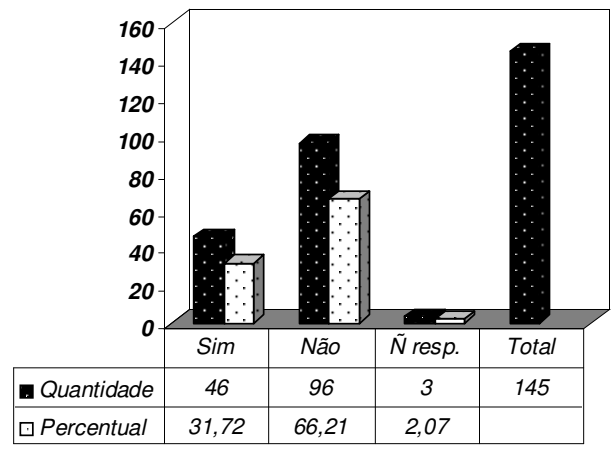

Figura 4-Gráfico que apresenta a quantificação do nível de conhecimento a respeito do Refúgio da Vida Silvestre Banhado dos Pachecos.

Foi realizado também o questionamento a respeito do Parque Estadual de Itapuã (Figura 5), com o objetivo de comparação, pois esta unidade é bem mais antiga em relação à APABG e ao Refúgio. Além disso, ela é muito visitada e está inserida no município de Viamão. Dessa forma, pode-se verificar se o tempo de existência e o acesso interferem no nível de conhecimento e no de proteção. Neste quesito foram observados os seguintes dados: 


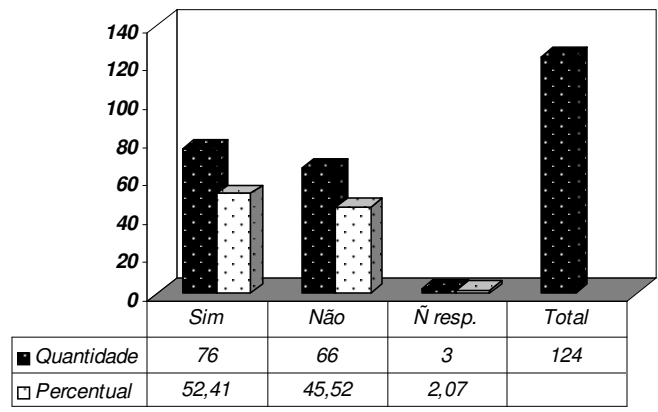

Figura 5 - Gráfico que apresenta a quantificação do nível de conhecimento a respeito do Parque Estadual Itapuã.

Com relação a segunda pesquisa, o mapeamento de ações em educação ambiental na APABG, a metodologia foi à pesquisa quantitativa tendo como instrumento a aplicação de um questionário com perguntas objetivas. Entretanto havia perguntas mais abertas, visando verificar a opinião dos entrevistados quanto a algumas questões mais subjetivas, porém estas também foram quantificadas. Foram analisados 14 questionários, seguem os resultados obtidos.

Quando questionados se conhecem a APABG e o Refúgio da Vida Silvestre Banhado dos Pachecos (RVSBP), obtiveram-se os seguintes resultados (Figura 6):

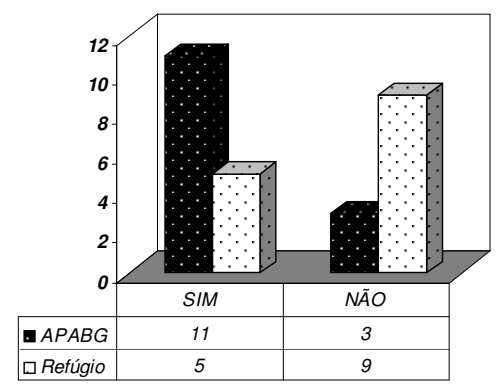

Figura 6 - Gráfico que apresenta o nível de conhecimento sobre a APABG e o RVSBP

Com relação ao desenvolvimento de ações em EA oito responderam que realizam atividades, cinco não responderam, mas uma dessas afirma que as atividades de EA se inserem nas rotinas de sala de aula, não havendo assim um projeto específico, e uma informa não ter nada específico. Os temas geradores mais citados foram: resíduos sólidos; saúde; fauna e flora; consumo consciente; e recursos hídricos.

Quanto à amplitude das ações a maioria afirma trabalhar com alunos, família e professores. Boa parte da coordenação dessas ações é realizada por professores das seguintes disciplinas: geografia; história, educação física, ciências, do currículo, da educação infantil, do 4o ano. Apenas em duas envolvem todos os professores. Alguns não especificaram os profissionais.

Ao se inquirir a respeito da relação que existe com a realidade local, oito escolas disseram que sim, não houve marcações para o não, e quatro não responderam. 
Das 14 instituições apenas quatro relataram que possuem parceiros, divididos em: públicos (2); privados (1) e sociedade civil ONG (1). Cinco afirmaram não possuir parcerias e igual número não responderam.

Com relação à forma como são desenvolvidas as ações, nove $(69,2 \%)$ informaram ser inter ou multidisciplinar, nenhum disciplinar e cinco não responderam. Quanto à forma de acompanhamento, dois afirmaram ser por relatórios e reuniões, três através de reuniões, dois não ocorre acompanhamento e sete não responderam. A maior parte das ações não é custeada (5), em duas há o custeio pelo poder público e uma por doação, seis não responderam.

As dificuldades enfrentadas estão distribuídas na tabela 1, a maioria das instituições assinalou mais de uma opção, portanto os números indicam a frequência com que foram citadas.

Tabela 1 - Dificuldades encontradas no desenvolvimento das ações em EA

Que dificuldades são encontradas:

\begin{tabular}{cc}
\hline Falta de qualificação continuada em EA & 3 \\
\hline Falta de políticas de investimento em EA & 4 \\
\hline Pouca participação/desinteresse do público-alvo & 5 \\
\hline Outras *: & 1 \\
\hline Não responderam & 6
\end{tabular}

* Falta de integração entre escolas e estas com SME

Em cinco instituições há profissionais com qualificação em EA, foram citados Pós em EA e Gestão Ambiental (o assessor da SME); curso de qualificação de 40h. Cinco informaram não haver pessoal qualificado e quatro não responderam.

\section{DISCUSSÃO}

Quanto à primeira pesquisa a maioria dos entrevistados são alunos do ensino fundamental, isso se torna importante, pois uma das premissas para o plano de EA para a APABG é iniciar o trabalho pelas escolas. Com base nestes dados pode-se perceber o nível de conhecimento determinando o ponto de partida e os objetivos a serem alcançados.

A primeira constatação é que não há um claro conhecimento a respeito do que seja unidade de conservação, mas quase todas que responderam sim possuem uma noção, pois fizeram referências como sendo locais de conservação e preservação da natureza.

Apesar de boa parte dos entrevistados serem moradores de Águas Claras/Viamão, onde boa parte da região se encontra inserida na APABG e onde está localizado o Refúgio da Vida 
Silvestre Banhado dos Pachecos, percebe-se um percentual elevado de desconhecimento sobre essas duas unidades de conservação. Isso consubstancia a ideia de que o simples estabelecimento de uma unidade de conservação não garante a efetiva preservação dos recursos naturais, se não vier acompanhado de um processo educativo que desenvolva o sentido de pertencimento e cidadania.

Esses dados demonstram a necessidade e a urgência de disseminação de informações a respeito da APABG e do Refúgio e, também, de formação em educação ambiental para os educadores, atores importantes na formação de cidadania, possibilitando conhecimentos que favoreçam o entendimento da complexidade, da interdependência e da interatividade entre os elementos desse ecossistema (MORIN, 2005, p. 38). Sendo a EA um "processo permanente" (DIAS, 2000, p. 171), certamente favorecerá a aquisição de competências e habilidades levando a comunidade a tomar consciência de seu meio.

Comparando os dados do nível de conhecimento do Parque Estadual de Itapuã com os das outras duas unidades de conservação constata-se que realmente ele é mais conhecido pelos moradores da região de Águas Claras. Provavelmente, isto se deve ao tempo de existência e a todo o histórico que o Parque Itapuã tem de luta e efetivação. E, também, a todo trabalho de incentivo a pesquisa e educação ambiental existente neste local, confirmando a importância desse tipo investimento. Portanto, incentivar a pesquisa científica e ações educativas são coisas que devem ser elencadas como prioridades no plano de EA da APABG.

Na segunda pesquisa, o mapeamento de ações em EA dentro e no entorno da APA, cabe esclarecer que essa foi uma proposta da Câmara Temática de EA do Conselho Deliberativo da APABG (da qual a autora desse artigo faz parte). Este mapeamento enfrentou muitas dificuldades de aplicação, tais como: custeio; mobilidade e acesso as instituições; o não retorno por parte do representante do município dos questionários e problemas que os entrevistadores encontraram em distribuir e aplicar a pesquisa. Foram distribuídos questionários a todos os quatro municípios, mas apenas três retornaram. De um pouco mais de 30 questionários enviados aos municípios apenas 14 regressaram.

Com base nos dados coletados verificou-se que todos os projetos possuem temas relevantes e relacionados à preservação do meio ambiente, visando à conscientização e formação de hábitos ecologicamente corretos, de cuidado com lixo e outros. Apesar de todos afirmarem ser inter e multidisciplinares, percebe-se que alguns são direcionados por uma ou duas disciplinas e também atendem a demandas pontuais. Entretanto, para saber se realmente são contextualizados e inter ou multidisciplinares necessitaria de um acompanhamento mais detalhado, o que não foi possível através desse mapeamento. Na maioria são os professores os profissionais envolvidos nas ações, com poucas parceiras e voluntariado, isso demonstra a importância de uma formação para professores direcionada e relacionada à APABG e ao Refúgio, pois essas unidades de conservação não foram citadas como temas geradores. Talvez, se estes profissionais tivessem sensibilizados e com o aporte de conhecimentos ecossistêmicos, da história e de tudo que se relaciona as unidades, pudessem desenvolver, primeiro em si, e depois nos alunos, o sentido de pertencimento, de cuidado e preservação e, quem sabe, a formação de lideranças locais capazes de atuarem e decidirem sobre questões relevantes da comunidade. Quando o indivíduo se sente integrado ao seu meio (VENDRAMETTO, 2004, p. 48), inter-relaciona as questões socioambientais ele se sente responsável por sua comunidade, participa, decide e age sobre seu meio. 
Das quatorze escolas entrevistadas apenas cinco possuem pessoal com qualificação, e nestas, se não houver uma política de EA, ou seja, se além de estar inserido no PPP da escola, não for uma prática de grupo, dificilmente um projeto se encaminha. Por isso a importância da inserção da formação continuada para todos os professores das escolas e outros educadores da comunidade no plano em EA para a APABG.

\section{CONCLUSÃO}

Considerando-se toda a realidade que a APABG enfrenta desde sua criação, como estabelecimento da Comissão de luta pela sua efetivação - Cleapa e de seu Conselho Deliberativo conclui-se que a construção de um Plano de Educação Ambiental será uma grande vitória.

A APABG possui muitas particularidades, entre as quais abranger quatro municípios, possuir grande diversidade de habitats, de fauna e flora e importância como fonte hídrica. Frente a isso, a grande degradação ambiental dos seus habitats, ser desconhecida por sua população e não possuir seu plano de manejo, reforça-se a importância desse Plano de Educação Ambiental.

Esse trabalho realizou um apanhado dessa realidade e reuniu alguns pressupostos teóricos que orientam e apontam possíveis caminhos para a sua elaboração. Para tanto, se usou uma metodologia de pesquisa que diagnosticou as ações em EA e o nível de conhecimento a respeito da APABG. Tanto os pressupostos teóricos como o resultado das pesquisas indicam a necessidade, a urgência e a viabilidade desse plano e, principalmente, o investimento em ações de formação dos educadores das instituições de ensino que se encontram dentro e no entorno da APABG.

Porém, frente às dificuldades enfrentadas no mapeamento das ações, sugere-se que este trabalho não se esgote por aqui, talvez outra metodologia de pesquisa mais próxima da realidade dos municípios seja necessário. Igualmente, torna-se imprescindível rever a forma de aplicação dos questionários, visto que o percentual de retorno foi baixo. Sugere-se também que a pesquisa realizada em Águas Claras seja expandida as demais localidades que compõem a APA. Ressalta-se a urgência na busca de recursos e parcerias para a construção desse plano, pois devido a sua extensão e o difícil acesso a algumas localidades da APA se faz necessário o aporte financeiro para transporte e para a formação.

\section{REFERÊNCIAS}

ACCORDI, I. A. Estrutura espacial e sazonal da Avifauna e considerações sobre a conservação de aves aquáticas em uma área umidade do RS, Brasil. 2003. 171 f. Dissertação (Mestrado em Ecologia) Universidade Federal do Rio Grande do Sul, Porto Alegre, 2003.

BRASIL. Lei n. 9.795, de 27 de abril de 1999. Dispõe sobre a educação ambiental, institui a Política Nacional de Educação Ambiental e dá outras providências. Diário Oficial da União, Brasília, DF, 28 abr. 1999. Disponível em: <http://www.mma.gov.br/port/conama/legiabre.cfm?codlegi=321>. Acesso em: 21 out. 2011.

. Lei n. 9.985, de 18 de julho de 2000. Cria o Sistema Nacional de Unidades de Conservação - SNUC. Diário Oficial da União, Brasília, DF, 18 jul. 2000. Disponível em: <http://www.planalto.gov.br/ccivil_03/leis/L9985.htm >. Acesso em: 12 ago. 2011. 
Ministério do Meio Ambiente. Identidades da Educação Ambiental Brasileira. Philippe P Layrargues [Coord.]. Brasília: MMA, 2004.

- Ministério da Educação. Ministério do Meio Ambiente. Programa Nacional de Educação Ambiental - ProNEA. Brasília: CID - Ambiental, 2005, 3ed.

CARVALHO, I. C. de M. Educação ambiental: a formação do sujeito ecológico. São Paulo: Cortez, 2004.

DIAS, G. F. Fundamentos de Educação Ambiental. Brasília: Universa, 2000.

G. F. Educação Ambiental: Princípios e Práticas. São Paulo: Gaia, 2003. 8. ed.

MORIN, E. Os Setes Saberes necessários a Educação do Futuro. São Paulo: Cortez; DF: UNESCO, 2005.

RIO GRANDE DO SUL. Secretaria da Agricultura e Abastecimento. Plano de Manejo Parque Estadual de Itapuã. Margô Guadalupe Antonio (Coord.). Porto Alegre: DRNR, 1996. Disponível em: <http://www.sema.rs.gov.br/upload/Plano_manejo_PEltapua.pdf>. Acesso em: 02 nov. 2011.

. Secretaria do Meio Ambiente. Banhado dos Pachecos está implementado. Portal

do Meio Ambiente, 10 jS, 2002 . Disponível em:

<http://www.sema.rs.gov.br/conteudo.asp?cod_menu=4\&cod_conteudo=2954>. Acesso em: 18 set. 2011.

- Secretaria do Meio ambiente. Unidades de Conservação. Proteger os ecossistemas é conservar a biodiversidade. RS, 2009.

. Secretaria do Meio ambiente. Portaria SEMA n. 025, 25 de junho de 2009. Cria o Conselho Deliberativo da Área de Proteção Ambiental - APA do Banhado Grande e dá outras providências. Disponível em: <http://www.sema.rs.gov.br/upload/Portaria\%2025_2009_Cria\%20Conselho\%20Deliberativo\%20\%C3\%81r ea\%20Prote\%C3\%A7ao\%20APA\%20Banhado\%20Grande.pdf>. Acesso em: 12 ago. 2009.

. Secretaria do Meio Ambiente. Termo de Referência para elaboração do Plano de Manejo da Área de Proteção Ambiental do Banhado Grande. DEFAP/DUC, Porto Alegre, 2010.

- Secretaria do Meio Ambiente. RS: cervos-do-pantanal são encontrados no Banhado dos Pachecos. Assessoria de Comunicação da SEMA/RS, 05 nov. 2010. Disponível em: <http://amarnatureza.org.br/site/rs-cervos-do-pantanal-sao-encontradas-no-banhado-dospachecos, 71740/>. Acesso em 29 set. 2011.

VENDRAMETTO, L. P. Educação Ambiental nas Unidades de Conservação: um estudo de caso na Área de Proteção Ambiental de Sousas e Joaquim Egídio. Piracicaba, SP, fev. 2004. Disponível em: <http://www.teses.usp.br/teses/disponiveis/11/11150/tde-06102004-165858/pt-br.php>. Acesso em 22 set. 2011. 